\title{
ВЛИЯНИЕ ВRЕХІТ НА ПОВЕДЕНИЕ БИЗНЕСА В ВЕЛИКОБРИТАНИИ
}

\section{BREXIT IMPACT ON THE GREAT BRITAIN BUSINESS BEHAVIOR}

A. Lyon

Summary. In this article, the Brexit impact on the UK economy, namely the business, is considered. The most characteristic aspects of the state economy certain indicators decline are considered, and their alleged dependence on Brexit is revealed and argued. A detailed analysis of foreign and domestic corporations share, their regional affiliation within the territory of Great Britain has been carried out. The dynamics of their number during the period of the main events related to Brexit, as well as the share of their contribution to the United Kingdom economy for the specified period is revealed. The main prerequisites and possible ways of leaving a foreign business from the UK in the current circumstances are investigated.

Keywords: UK, European Union, Brexit, business, foreign business, jurisdiction.
B еликобритания долгое время сохраняет одну из лидирующих позиций в мировом рейтинге финансовых центров по данным Long Finance [19]. А также, по данным Forbes [12], на начало 2020 г. по-прежнему занимает лидирующее место среди стран, наиболее благоприятных для ведений бизнеса. Однако, привлекательность Великобритании для ведения бизнеса может сильно пошатнуться из-за Brexit: членство Великобритании в ЕС прекратилось 31 января 2020 г. [4], несмотря на многократный перенос даты этого события, что было обусловлено жесткими разногласиями как между ведущими партиями в парламенте, так и внутри самого британского правительства [5].

На наш взгляд, Brexit является критичным решением для Европы. Причиной тому становятся не столько экономические факторы, сколько сам факт того, что Brexit создает прецедент, который может послужить примером для других стран и их регионов, к примеру, Каталонии [1]. Так, сходство темы «каталонского вопроса» и Brexit заключается, преимущественно, в попытках отделения административной единицы от наднациональной (в случае Великобритании) или государственной (Испании) структуры. Так же, как и в Великобритании, ключевым аспектом отделения Каталонии от Испании являлся высокий уровень самодостаточности экономики региона и не желание поддерживать прочие регионы в условиях экономического кризиса. Как и в случае Великобрита-
Лион Алексей Алексеевич

Аспирант, ФГБНУ «Национальный исследовательский институт мировой экономики и международных отношений имени Е. М. Примакова

Российской академии наук» Alexey.lyon@gmail.com

Аннотация. В данной статье рассмотрено влияние Brexit на экономику Великобритании, а именно на сферу бизнеса. Рассмотрены и проанализированы ключевые показатели экономики государства, а также выявлена и аргументирована их предполагаемая зависимость от Brexit. Проведен подробный анализ доли иностранных и отечественных корпораций, их региональной принадлежности в рамках территории Великобритании. Выявлена динамика их количества в период протекания основных событий, связанных c Brexit, a также доли их вклада в экономику страны за указанный период. Исследованы основные предпосылки и возможные пути ухода иностранного бизнеса из Великобритании в сложившихся условиях.

Ключевые слова: Великобритания, Европейский союз, Brexit, бизнес, иностранный бизнес, юрисдикция.

нии, и формирования партии UKIP, в Каталонии в 2005 г. была сформирована центристская партия «Cuidadanos», основной идей которой являлось автономия Каталонии, аргументирующая собственные позиции тезисами о весомом вкладе Каталонии в общую экономику Испанского королевства [10].

Однако, Brexit влияет отнюдь не только на Каталонию. Прецедент, созданный Великобританией, наглядно показывает неустойчивость геополитического положения в Европе. Что, в свою очередь, может дополнительно усугубить многочисленные конфликты между странами и регионами ЕС. Р.В. Костюк и Д.А. Рущин обращают отдельное внимание на схожесть экономических детерминант Каталонии и Великобритании [7]. Проводя отсылки к референдуму в Каталонии в 2014 г., можно говорить о нем, как о, своего рода, аналоге проведения шотландского референдума. Явка на Каталонский референдум составила 33\%, в то время, как явка на референдум, проведенный в Шотландии - 84,6\%. Основное различие между каталонским вопросом и ситуацией в Шотландии заключается в том, что если Шотландия, выступавшая против Brexit, намерена отделиться от самой Великобритании и войти в ЕС, то Каталония преследует цель обрести полную независимость [6]. В случае возвращения в ведомство Шотландии $80 \%$ находящихся на ее территории ресурсов, которыми на данный момент владеет Великобритания, ВВП Шотландии вырастет на 22\%, что 
позволит ей занять 8 место в рейтинге стран по величине ВВП [3]. Поведение Шотландии на политической арене, обусловленное теми же желаниями, которые высказывала Великобритания - увеличением дохода и наращиванием капитала, имеет несколько другой вектор развития, что также можно назвать предпосылкой для ее возможного стремления к автономии.

Достаточно обостренным вопросом, с точки зрения геополитической и экономической ситуации Великобритании, является вопрос границы Северной Ирландии с Ирландией, который, в случае наихудшего развития событий, может привести к повторному обострению вооруженного конфликта, завершенного подписанием Белфастского соглашения в 1998 г., что также может оказать чрезвычайно пагубное воздействие на состояние экономики Великобритании. Согласно данным Office of National Statistics на ноябрь 2018 г. доли Северной Ирландии и Шотландии в ВВП Великобритании составляют $7,7 \%$ и 2,1\% соответственно [17], что еще более подчеркивает важность сохранения единства Великобритании с точки зрения стабилизации ее экономики в условиях Brexit. При этом, важно отметить, что Великобритании пришлось сменить два правительства, чтобы добиться выхода из ЕС, но самая сложная часть переговоров о Brexit еще впереди [19]. Речь идет о том, что до конца 2020 г., как уже говорилось ранее, государству предстоит заключить новые торговые соглашения с ЕС, США и многими другими странами. Пока же, Великобритания будет оставаться частью единого европейского рынка и Таможенного союза ЕС, что позволяет беспошлинное обращение товаров. Однако, несмотря на устойчивое состояние экономики Великобритании, неопределенность условий Brexit не может не рождать опасения у бизнеса, особенно у его иностранных компаний. Дальнейшее будущее британских товаров, как и европейского экспорта в Соединенное Королевство, будет зависеть от того, удастся ли Лондону и Брюсселю договориться о беспошлинной торговле. По оценкам Bloomberg, если такие переговоры провалятся и Британия введет пошлины на товары из ЕС, они в сумме могут достигать 5 млрд. евро ежегодно.

Важным фактором является значительное снижение темпа роста ВВП, который на 2019 г. составил 1,3\%, что является самым низким показателем с 2009 г., а также отрицательная динамика ценности национальной валюты. Более того, по прогнозам Банка Англии, в 2020 г. темп прироста ВВП страны составит 0,8\%, а через год - 1,5\% [11]. Безусловно, это самым непосредственным образом окажет негативное воздействие на уровень заинтересованности и, как следствие, привлечения иностранного бизнеса на территорию государства. Однако, проводя сравнительный анализ темпа роста Великобритании, Франции и Германии за основной период протекания событий, связанных с Brexit, а именно за 2014-2019 гг., следует отметить резкий спад темпа роста ВВП для каждой из рассматриваемых стран. Это может быть связано, в первую очередь, с экономическим кризисом и общим состоянием экономики ЕС в данном периоде, однако резкое увеличение темпа роста ВВП Германии и Франции в период 2016-2018 гг. наравне с сохраняющейся тенденцией спада этого же показателя Великобритании позволяет нам связывать упадок данного показателя с Brexit.

\section{В^ияние Brexit на бизнес в Великобритании}

Согласно данным Global Open Data Index на 20152016 гг. Великобритания занимала 4 место в глобальном мировом рейтинге привлекательности государств для регистраций предприятий [15]. Простота процедуры регистрации была определена важнейшей особенностью экономики Великобритании в сфере бизнеса по шкале Doing Business 2019 эта категория набрала 95,58 баллов из 100 возможных, что является чрезвычайно высоким показателем на международном рынке. На конец февраля 2020 г. данный показатель снизился, однако не столь значительно - до 94,6 баллов [14]. Также, дополнительным преимуществом следует отметить достаточную стабильность процедуры регистрации бизнеса, которая по отношению к 2018 г. не была изменена и сохранила максимальную прозрачность. В ходе проведения процедуры первым этапом является определение названия компании, заполнение первой формы заявки, которая включает в себя соответствующую графу и страну регистрации предприятия, тип и форму предпринимательства. Этот этап проходит онлайн и длится до одного дня, при этом сопровождается достаточно умеренным первым взносом в размере 12 ф. ст. Последующие этапы регистрации не требуют повторных и поточных взносов. По завершению первого этапа последующим является подача заявки в государственный регистр Великобритании. Длительность данного этапа составляет один рабочий день. Последующим этапом регистрации предприятия является заключение контракта регистра PAYЕ (системы сбора подоходного налога) и HMRC (государственного департамента Великобритании). Данный этап является наиболее длительным во всей процедуре и может длиться до трех рабочих дней. После чего следует последний этап -этап регистрации страховых документов сотрудников, который занимает до одного рабочего дня. Простота данной процедуры, в совокупности с налоговым законодательством в указанной сфере, является одной из наиболее привлекательных для иностранного бизнеса на международном рынке, что также долгое время позволяло обеспечивать прирост количества предприятий в юрисдикции Великобритании. 
Согласно государственной статистике, в 2018-2019 фин. гг. на территории Великобритании было зарегистрировано 4,2 млн. предприятий, 3,9 млн. из которых зарегистрированы в Англии и Уэльсе, 217 тыс.- в Шотландии и 62 тыс.- в Северной Ирландии [17]. При этом, четырьмя годами ранее, в 2015-2016 фин. гг., в Великобритании было зарегистрировано 3,5 млн. предприятий, что на 300 тыс. больше показателя 2018 г. При этом, важно, что на 2019 г. более 49,1 тыс. компаний являются иностранными предприятиями, находящимися в ее юрисдикции. Однако, несмотря на продолжающийся рост общего числа зарегистрированных компаний на территории Великобритании, с момента проведения референдума 2016 г. наблюдается отрицательная динамика по приросту регистрации компаний, а именно его снижении более чем в два раза. Таким образом, если на 2015-2016 фин. гг. рост числа компаний, находящихся в реестре, составлял 6,7\% от общего количества, то к 2018-2019 фин. гг. данный показатель снизился до 4,2\%. В период с 2013-2014 фин. гг. по 2015 фин. г. показатели имели положительную динамику, а именно увеличились с 6,4\% до 7,4\%. К 2015-2016 гг. наблюдался несущественный спад с 7,4\% до 6,7\%. Аналогичным образом обстояла ситуация к 2016-2017 фин. гг., которая охарактеризовалась спадом с 6,7\% до 5,9\%. Временной период относительно полученных данных позволяет связать данный спад показателей с итогами референдума о выходе Великобритании из Европейского Союза, а именно с приближением даты Brexit на неизвестных условиях.

Сравнительный анализ показателей регистрации новых компаний по отдельным регионам страны говорит об их, пусть и несущественном, изменении в сторону спада: на территории Шотландии - с 4,8\% до 3,7\%, на территории Северной Ирландии - с 7,1\% до 5,6\%. Наиболее резкий спад данных показателей наблюдается в отношении Англии и Уэльса - с 5,9\% до 3,2\%, что говорит о резком падение числа зарегистрированных фирм практически вдвое. Таким образом, по обобщенным данным на территории Англии и Уэльса за указанный период заявило о закрытии 13,2\% от всех компаний, а в Шотландии и Северной Ирландии - 4,3\%. С точки зрения территориальной принадлежности рост новых регистраций предприятий на территории Англии и Уэльса составил 1,3\%. А на территории Шотландии и Северной Ирландии - 4,1\%, что в целом в 3 раза превышает аналогичные показатели в регионах, поддержавших Brexit в процессе проведения референдума 2016 г.

На 2016 г. в Великобритании были зарегистрированы более 100 тыс. иностранных компаний, что составляет 3,6\% от общего числа предприятий, зафиксированных в государственном регистре. Однако, следует отдельно отметить значимость вклада иностранных компаний
В экономику Великобритании, т.к. суммарный оборот этих компаний составил почти 1,2 трлн. ф. ст., что, В свою очередь, составило 34,1\% от оборота всех компаний, зарегистрированных на территории этого государства. При этом, большинство доходов от иностранных компаний приходились на один регион: из 1,2 трлн. ф. ст. общих оборотов иностранных компаний более 1 трлн. ф. ст. был получен иностранными компаниями, зарегистрированными на территории Англии, что составило около 83\% от всех доходов компаний, принадлежащих иностранцам. В остальных регионах Великобритании на тот период было зарегистрировано суммарно всего 14,2 тыс. иностранных компаний (из 101 тыс. по всей территории государства), которые имели суммарные обороты около 123 млрд. ф. ст., что составляет только порядка 10\% от суммарного оборота всех иностранных компаний на территории Великобритании. Таким образом, видно, что иностранные компании главным образом сконцентрированы в Англии, приносят более 1/3 всех оборотов компаний в Великобритании и составляют важную часть британской экономики. По странам происхождения иностранные компании, зарегистрированные в Великобритании, делятся следующим образом: около 60 тыс. компаний европейские (59\% от всех иностранных компаний Великобритании), 32 тыс.- из Северной и Латинской Америк (32\%), 5 тыс.- азиатские (5\%), 4 тыс.- прочие юрисдикции (4\%). Десять ведущих стран, в которых в 2018-2019 гг. были зарегистрированы британские компании, где лидером выступает США (21,7\%), соответствуют показателям прошлого фин. г. На эти страны приходилось 63,1\% всех иностранных юридических лиц в общем реестре на конец марта 2019 г. помимо этого, из общего числа зарегистрированных иностранных компаний в юрисдикции Великобритании на 2019 г. 13,0\% составляют фирмы Нормандских островов, 9,5\% составляют компании Ирландской Республики. Согласно данным государственной статистики Великобритании, с 2013 г. число зарегистрированных иностранных предприятий увеличилось на 1355 ед. [17].

Таким образом, территориальная принадлежность исследуемых показателей в соответствии с отношением данных регионов к выходу из ЕС, а также временным периодам по отношению к их количественным изменениям, позволяет допускать аргументированные предположения о взаимосвязи с негативной реакцией представителей зарубежного бизнеса на территории Великобритании на Brexit.

\section{ПреАпосылки и возможные пути ухоАа иностранного бизнеса из Великобритании в условиях Brexit}

На фоне нестабильности ситуации, обусловленной выходом Великобритании из состава ЕС на начало 2020 г. 
существует ряд предпосылок для ухода множества иностранных компаний, зарегистрированных на ее территории в страны Еврозоны. Одной из основных причин являются возможные сложности в торговле с континентальной Европой, на которой полностью завязан бизнес международных компаний острова. Одновременно с этим, на в течение 2020 г. планируется два раунда переговоров по поводу дальнейшего взаимодействия Великобритании и ЕС. Первый раунд переговоров проходит в Брюсселе с участием главных переговорщиков М. Барнье (ЕС) и Д. Фроста (Великобритания). По сообщению Reuters, «обе стороны заявляют, что хотят достичь соглашения до конца года, чтобы с 2021 началось новое сотрудничество по всем направлениям, от авиации до рыболовства и обмена студентами». Второй раунд переговоров состоится в Лондоне. «ЕС хочет предоставить Британии выгодный доступ к единому рынку в обмен на надежные гарантии того, что Лондон предотвратит демпинг. Но премьер-министр Великобритании Борис Джонсон ранее заявлял, что хочет отойти от ЕС и отказывается подчиняться его правилам или юрисдикции его высшего суда - все это необходимо, по мнению блока, для обеспечения честной конкуренции» [6].

Наравне со странами ЕС, США является стратегическим партнером Великобритании в сфере бизнеса и торговли: на ее долю в 2019 г. приходилось 21,7\% зарегистрированных иностранных компаний на территории Великобритании, а также $11 \%$ от общего экспорта, 7,5\% импорта. По данным опроса более 533 руководителей американских компаний с оборотом не менее 10 миллионов фунтов, проведённого Gowling WLG в период с 21 сентября по 18 октября 2016 г., до 40\% из них рассматривают возможность переноса своих британских офисов в другие страны ЕС. Более трети компаний, занимающихся экспортом в зону ЕС, заявили, что два года неопределенности в сфере регулирования торговых отношений могут нанести непоправимый вред их бизнесу, в связи с чем они предполагают вести дальнейшую торговлю напрямую с ЕС в обход Великобритании. По заявлению руководителя консалтинговой компании Gowling WLG Б. Адкинс в связи со сложившейся ситуацией «Прочные торговые отношения между Великобританией и США, которые тщательно развивались в течение последних пятидесяти лет, находятся под серьезной угрозой» [13].

Согласно опросу Ernst \& Young, 222 компании Великобритании намерены переехать в другие юрисдикции. При этом с 2017 г. данный показатель вырос только на 1\%, и на 2\% суммарно с 2016 г. Несмотря на это, фактические переезды массово начали происходить уже в 2018 г. Так, в июне 2018 г., страну покинули 24\% компаний, заявивших ранее о собственных намерениях, в марте 2018 г.- 21\% компаний, а в декабре 2017 г.-
19\%. После Brexit-прецедента стремительно увеличивается динамика роста числа «бизнес-эмигрантов». Таким образом, сразу же после референдума 2016 г., 34\% компаний подтвердили, что покидают Великобританию, из них 24\% выбрали Дублин в качестве своего нового места расположения. По данным на март 2019 г. (ожидалось, что 29 марта 2019 г. Великобритания выйдет из Е(), из частного сектора ушли 508,8 тыс. компаний, что на 3,7\% больше, чем в прошлом году. Более того, согласно мартовскому отчету аналитического центра New Financial из 275 опрошенных банковских и финансовых компаний, отреагировавших на Brexit, 250 переместили или перемещают бизнес, персонал, активы или юридические лица из территории Великобритании в ЕС. Более 210 из них уже зарегистрировали новые юридические лица и получили новые лицензии. Банки переместили или находятся в процессе перемещения своих активов на сумму около 800 млрд. ф. ст. в страны ЕС, страховые и финансовые компании также перевели более 65 млрд. ф. ст. своих активов в фонды вне территории Великобритании. Важно отметить, что согласно прогнозам центра, эти показатели значительно увеличатся в ближайшем будущем. Дублин, основываясь на статистические данные того же отчета, является крупнейшим центром для перенесения бизнеса из Великобритании в данный момент. Имея показатель в 100 компаний, выбравших его для смены местоположения своей деятельности, он значительно опережает Люксембург с 60, Париж с 41, Франкфурт с 40 и Амстердам с 32. При этом данные различных секторов в рамках опрошенной группы весьма разнообразны: например, почти половина управляющих активами, хедж-фондов и частных инвестиционных компаний выбрали Дублин, в то время как почти 90\% фирм, переезжающих во Франкфурт, являются банками или инвестиционными банками [20].

Таким образом, согласно приведенным опросам и исследованиям Дублин, является наиболее популярным выбором для перенесения бизнеса из территории Великобритании в ЕС. Стоить отметить, что наиболее часто ему отдают предпочтение компании из сектора страхования. Франкфурт-на-Майне стал наиболее частым выбором компаний из финансового сектора, и Люксембург - компаний в сфере услуг и управления. Несмотря на то, что именно Дублин занимает лидирующие позиции среди мест, куда отправится британский бизнес, также Франкфурт-на-Майне серьезно привлекает компании. Его привлекательность для перенесения бизнеса в условиях Brexit аргументируется тем, что Германия является вторым, после Америки, партнером Великобритании в области портфельных инвестиций. На 2015 г. на ее территории находилось всего 100 немецких заводов, большинство из которых имело отношение к автомобильной промышленности, занимающей $25 \%$ всего экспорта Германии. Процесс перерегистрации во Франкфурте уже 
прошли такие компании, как Morgan Stanley, Citigroup, Deutsche Bank и др. Помимо автомобильной промышленности и фармацевтической отрасли, в группе тех, кто стремится выйти с британского рынка, оказались также банки, компании по транспортным и пассажирским перевозкам. Так, в тот же Франкфурт переехали Nomura, Ведомство Банковского Надзора Европы, Daiwa и ретейлер Muji, Easy Jet, Microsoft, Diageo и др. также оказались среди «эмигрантов». В Брюссель отправится Европейское агентство по лекарственным делам. Вне зоны риска от Brexit оказались майнинговые компании и табачные корпорации. Гостиннично-ресторанный бизнес и технологическая сфера также остаются на острове.

\section{Выво $\triangle \mathrm{b}$}

В условиях неопределенности позиций Великобритании в рамках выхода из ЕС, их внутренних проблем, а также спада роста ВВП, который в 2019 г. составил 1,3\%, что является самым низким показателем с 2009 г., и показателей прочих экономических факторов невозможно отрицать многогранность сложившейся ситуации для бизнеса в юрисдикции данного государства. Так, несмотря на лидерство в рейтинге стран, наиболее благоприятных для ведений бизнеса, неопределенность в ставках налогообложения для множества процедур после Brexit, возможность ограничения открытости рынка территорией государства, Ирландский вопрос и множество других факторов уже сейчас оказывает достаточно сильное влияние на бизнес на территории Великобритании. Наиболее частой реакцией которого становится перенос своих офисов и активов на территорию ЕС. Так, достаточно большое количество иностранных компаний - более $30 \%$ от ранее заявивших о собственных намерениях, только в 2019 г. вышли из ее юрисдикции. Нельзя также преуменьшать фактор влияния Brexit и на британский бизнес, т.к. страны ЕС по-прежнему занимают наибольшую долю в рейтинге стран, в которые экспортируются товары из Великобритании - за 2018 г. данный показатель составил 291 млрд. ф. ст. (45\% всего экспорта) [8]. Однако, получение независимости от ЕС и его законодательных ограничений, а также возможность подписания новых, более выгодных договоров с основными стратегическими партнерами также могут стать определенным «толчком», способствующим развитию британского бизнеса и привлечении иностранных компаний на ее территорию.

В целом, на данный момент сложившаяся ситуация, обусловленная неопределенностью последствий Brexit, не позволяет множеству экспертов достигнуть единогласия в данном вопросе. Так, за 3,5 года, прошедшие с момента голосования британцев за выход из ЕС, было опубликовано множество прогнозов о том, какой экономический ущерб в ближайшей перспективе принесет Brexit как самой Великобритании, так и ЕС. Анализ 12 разных моделей весной 2019 г. представил Институт мировой экономики Петерсона (Вашингтон, США) [16]. Согласно исследованию, потери Великобритании варьируются от $-1,2$ до $-4,5 \%$ ее ВВП - в том случае, если стране не удастся заключить торговое соглашение с ЕС и стороны вернутся к торговле по правилам ВТО. Если же соглашения удастся достичь, эти потери удастся «смягчить» примерно вдвое. При этом, ЕС (в отличие от Британии) удастся компенсировать большую часть потерь в экспорте и импорте из Великобритании - из-за увеличения объемов торговли внутри ЕС и торговли с третьими странами.

\section{ЛИТЕРАТУРА}

1. Байков А. А. Дымов А. А. Выход Великобритании из ЕС и устойчивость европейской региональной структуры // Современная Европа. 2017. № 3 (75). C. 37-46

2. «Брексит» определился с датой и временем. Британия выйдет из Евросоюза 29 марта 2019 года. — 10.11.2017 // «Kommepсантъ».— ULR: https://www. kommersant.ru/doc/3464093 (дата обращения: 18.02.2020)

3. Васильев В. А. Движение за независимость Шотландии: ретроспективный анализ и современное состояние // Свободная мысль. 2014. № 5 (1647). С. 135-148

4. Ведник Ю. Британия выйдет из ЕС 31 января. Палата общин одобрила план Бориса Джонсона. — 20.12.2019// BBC. — ULR: https://www.bbc.com/russian/ news-50871391 (дата обращения 23.02.2020)

5. Гусаров С. и др. «Карусель брексита продолжает вращаться»: парламент в третий раз отклонил сделку Мэй по выходу из EC. - 29.03.2019 // RT. - ULR: https://russian.rt.com/world/article/616570-velikobritaniya-breksit-evrosoyuz (дата обращения: 22.02.2020)

6. ЕС и Великобритания начинают переговоры относительно будущих отношений после Brexit. — 02.03.2020 // Европейская правда. — ULR: https://www. eurointegration.com.ua/rus/news/2020/03/2/7106989/ (дата обращения: 02.03.2020)

7. Дронова С. Ю. Центробежные процессы в Великобритании и Испании в контексте Brexit // Гуманитарные науки. Вестник Финансового университета. 2017. № 1 (25). С. 73-79.

8. Костюк Р.В., Рущин Д. А. Каталонский тупик и новые сепаратистские вызовы в Европе. Дискуссионный семинар в СПбГу. Санкт-Петербург, 26 февраля 2018 г // 0бщество. Среда. Развитие (Terra Humana). 2018. № 1 (46). С. 172-173

9. Отсоединенноекоролевство. ТривопросаопоследствияхВrexitдляВеликобритании.—31.01.2020//PБK. —ULR:https://www.rbc.ru/newspaper/2020/01/31 (дата обращения: 29.02.2020) 
10. Худолей К.К., Еремина Н. В. Брекзит: новый «старый» выбор Великобритании // Современная Европа. 2017. № 3 (75). С. $28-36$.

11. Яковлев П.П. «Каталонский узел»: политические последствия экономического кризиса в Испании // Сетевое издание Центра исследований и аналитики ФИП («Перспективы»). 2015. № 4. С. 46-61.

12. Bank Rate maintained at 0.75\%. - 30.01.2020 // Официальный сайт Банка Англии. — ULR: https://www.bankofengland.co.uk/monetary-policy-summaryand-minutes/2020/january-2020 (дата обращения: 25.02.2020)

13. Best Countries for Business // Forbes. — ULR: https://www.forbes.com/best-countries-for-business/list/ (дата обращения 14.02.2020)

14. Brexit endangers U.S.-UK trade as some U.S. firms could move: report. - 14.12.2016 // Reuters. — ULR: https://www.reuters.com/article/us-britain-eu-usacompanies-idUSKBN14300G (дата обращения: 01.03.2020)

15. Ease of doing business in United Kingdom // Портал «Doing Business» — URL: http://www.doingbusiness.org/en/data/exploreeconomies/united-kingdom (дата обращения: 25.02.2020)

16. Great Britain // Портал «Global Open Data Index»_— URL: https://index.okfn.org/place/gb/ (дата обращения: 25.02.2020)

17. Latorre M.C., Olekseyuk Z., Yonezawa H., Robinson S. Brexit: Everyone Loses, but Britain Loses the Most // Working Paper. 2019. № 19-5. 21 p.

18. Official Statistics. Companies register activities: 2018 to 2019 // GOV.UK — URL: https://www.gov.uk/government/publications/companies-register-activitiesstatistical-release-2018-to-2019/companies-register-activities-2018-to-2019 (дата обращения: 28.02.2020)

19. Pogkas D., Diamond J.S. The EU Risks Tariffs on €47 Billion Without a Brexit Trade Deal.— 28.01.2020 // Bloomberg. — ULR: https://www.bloomberg.com/ graphics/2020-no-deal-brexit-trade-tariffs-european-union/ (дата обращения: 25.02.2020)

20. Press Release: Global Financial Centres Index 26. - 19.09.2019 // Long Finance. — ULR: https://www.longfinance.net/programmes/financial-centre-futures/ global-financial-centres-index/press/press-release-global-financial-centres-index-26/ (дата обращения 11.02.2020)

21. Wright W., Benson C., Hamre E. F. Report: Brexit \& the City — the impact so far.— March 2019. — ULR: https://newfinancial.org/the-impact-of-brexit-on-thecity/ (дата обращения: 02.03.2020)

( ) Лион Алексей Алексеевич ( Alexey.lyon@gmail.com ).

Журнал «Современная наука: актуальные проблемы теории и практики»

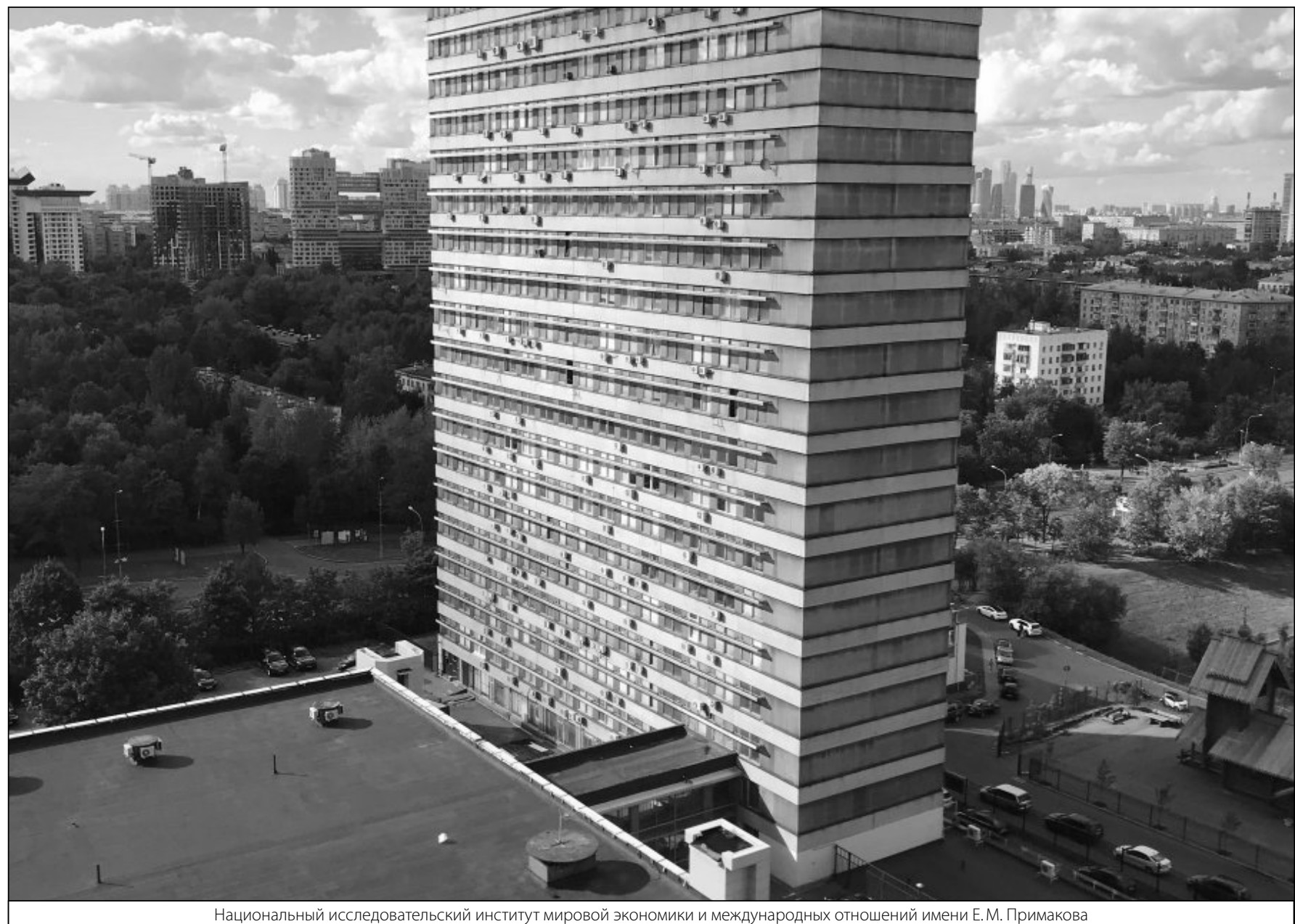

